\title{
Impactos Socioeconômicos da Atividade de Construção Civil no Programa Minha Casa Minha Vida na Cidade de Campo Grande/MS
}

\author{
Socioeconomic Impacts of Civil Construction Activity in the Minha Casa Minha Vida \\ Program in the City of Campo Grande / MS
}

\author{
Ayron Vinícius Pinheiro de Assunção*a; Breno Dutra de Queiroz ${ }^{\text {a; }}$ Helaine Clicia L Coutinho ${ }^{\mathrm{a}}$
}

${ }^{a}$ Centro Universitário Anhanguera de Campo Grande. MS, Brasil.

*E-mail: ayron.assuncao@anhanguera.com

\begin{abstract}
Resumo
O presente estudo aborda a questão dos impactos socioeconômicos e a sua relação com a construção civil na cidade de Campo Grande/MS, a partir da implementação do Programa Minha Casa Minha Vida. Objetiva-se com a pesquisa avaliar se houve mudanças no setor da construção civil em decorrência da participação do governo federal no projeto de construção de habitação popular, com a finalidade de fortalecer o setor da construção civil. Este setor teve mudanças com a presença do Programa Minha Casa Minha Vida, em face de se apresentar um elevado crescimento do setor imobiliário na cidade de Campo Grande, especialmente em função das demandas de habitação que se apresentam para os segmentos pertencentes aos estratos da classe baixa, média e alta. Adotou-se a pesquisa bibliográfica e documental para a realização do estudo, mediante o uso de fontes informativas de empresas do setor imobiliário que atuam na cidade de Campo Grande. Verifica-se que com a implantação do Programa Minha Casa Minha Vida na cidade de Campo Grande, o setor imobiliário por ter um elevado crescimento, decorrente das demandas, as empresas de construção civil continuam a expandir suas atividades para atender esse segmento social. Com isso, conclui-se que a proposta do governo para fortalecer as empresas de construção civil é atrativa para o setor construir casas e residenciais.
\end{abstract}

Palavras-chave: Impactos Socioeconômicos. Construção Civil. Habitação.

\begin{abstract}
The present study addresses the issue of socioeconomic impacts and their relationship with civil construction in the city of Campo Grande I MS, as a result of the implementation of the Minha Casa Minha Vida Program. The objective of the research is to evaluate whether there have been changes in the construction sector due to the federal government's participation in the popular housing construction project, with the purpose of strengthening the civil construction sector. This sector has changed with the presence of the Minha Casa Minha Vida Program, due to the high growth of the real estate sector in the city of Campo Grande, especially due to the housing demands that are present for the segments belonging to the low-income strata, medium and high. We adopted bibliographical and documentary research to carry out the study, using information sources from real estate companies operating in the city of Campo Grande. With the implementation of the My Home My Life Program in the city of Campo Grande, the real estate sector, due to its high growth, due to the demands, construction companies continue to expand their activities to serve this social segment. With this, it is concluded that the government's proposal to strengthen construction companies is attractive for the sector to build homes and residential.
\end{abstract}

Keywords: Socioeconomic Impacts. Construction. Housing.

\section{Introdução}

A construção civil nos últimos anos constitui num dos setores da atividade econômica em desenvolvimento. Esses eventos vêm de encontro com movimentos ocorridos no século XX, a combinação de fatores relacionados a crise fiscal e previdenciária do Estado, movidos pelo advento da Terceira Revolução Industrial que desencadeou severas transformações fizeram surgir por meio de relações sociais de produção até a reprodução do cotidiano ou seja, meios de produção e família, com isso surge as novas redes socioespaciais globalizando a vida social (SANTOS, 1997).

Entretanto a questão habitacional no Brasil tem sido objeto de discussão nos planos social, econômico e político, em função da necessidade de garantir os direitos sociais da população como parte integrante do dever do Estado na promoção da organização do espaço urbano e rural para atender as demandas sociais.

O financiamento da habitação por meio do Estado teve como eixo fundamental a contribuição da classe trabalhadora, mediante recursos oriundos do Fundo de Garantia Por Tempo de Serviço - FGTS, criado na década de 1960, culminando com a construção de imóveis residenciais destinados à classe média.

Nesse contexto se insere o Programa "Minha Casa, Minha Vida" (PMCMV) que, apesar de surgir, inicialmente, como uma ferramenta "anti-cíclica" do governo frente à crise econômica internacional, também se destaca pela sua proposta social. Com a meta de construir 1 milhão de moradias, sendo parte destas destinada à população de baixa renda (historicamente um dos principais gargalos da política habitacional) e considerável aporte de recursos do próprio Orçamento Geral da União (OGU), o Programa ganha relevância e representatividade para a política habitacional 
como um todo.

Neste sentido, o artigo busca demonstrar como os impactos socioeconômicos da atividade de construção civil se materializam na produção do espaço urbano a partir de uma análise sobre a Habitação de Interesse Social com um recorte para o Programa Minha Casa, Minha Vida.

\section{Desenvolvimento}

\subsection{Metodologia}

A opção pela escolha dessa metodologia foi definida em função dos objetivos pretendidos para a compreensão do objeto eleito, elegendo-se a técnica da pesquisa bibliográfica e documental. Segundo Santos, Calíope e Barros Neto (2017) a pesquisa qualitativa tem natureza distinta e finalidade independente à pesquisa quantitativa pois ela abrange aspectos que esta última não consegue abarcar. A pesquisa qualitativa é aquela que não utiliza modelos matemáticos ou estatísticos e sim textos, sons e até métodos não verbais Guba e Lincoln (2005).

\subsection{Conhecendo a cidade de Campo Grande/MS}

Campo Grande é um município brasileiro da região Centro-Oeste, capital do estado de Mato Grosso do Sul. Reduto histórico de divisionistas entre o sul e o norte, Campo Grande foi fundada há mais de 111 anos por colonizadores mineiros, que vieram aproveitar os campos de pastagens nativas e as águas cristalinas da região dos cerrados. A cidade foi planejada em meio a uma vasta área verde, com ruas e avenidas largas. Relativamente arborizada e com diversos jardins por entre as suas vias, apresenta, ainda nos dias de hoje, forte relação com a cultura indígena e suas raízes históricas. Por causa da cor de sua terra (roxa ou vermelha), recebeu a alcunha de Cidade Morena. A cidade está localizada em uma região de planalto, em que é possível ver os limites da linha do horizonte ao fundo de qualquer paisagem. O aquífero Guarani passa por baixo da cidade.

Campo Grande está localizada equidistante dos extremos norte, sul, leste e oeste de Mato Grosso do Sul, fator que facilitou a construção das primeiras estradas da região, contribuindo para que se tornasse a grande encruzilhada ou polo de desenvolvimento de uma vasta área.

A população economicamente ativa do município totaliza 333.597 pessoas (189.202 homens e 144.396 mulheres) e seu potencial de consumo é de $0,58 \%$ (est. 2006). De um modo geral, a maior parte da mão-de-obra ativa do município é absorvida pela setor terciário (comércio de mercadorias e prestação de serviços). A construção civil também desempenha papel muito importante na economia local.

\subsection{Sistema Financeiro de Habitação}

Em 1964, já durante o governo militar, surgiu, pela Lei 4.380/64, o Banco Nacional da Habitação, como órgão responsável por orientar, disciplinar e controlar o Sistema
Financeiro de Habitação (SFH). O objetivo da criação deste sistema era facilitar o acesso da população ao crédito imobiliário, atuando no combate ao déficit habitacional crescente, da ordem de sete milhões de domicílios (MARQUES, 2005), tendo em vista a intensificação dos processos de urbanização e aceleração do crescimento demográfico. Nas palavras de Bonduki (1983, p.72):

Foi uma resposta do governo militar à forte crise de moradia presente num país que se urbanizava aceleradamente, buscando, por um lado, angariar apoio entre as massas populares urbanas, segmento que era uma das principais bases da sustentação do populismo afastado do poder e, por outro, criar uma política permanente de financiamento, capaz de estruturar em moldes capitalistas o setor da construção civil habitacional, objetivo que acabou por prevalecer.

A criação do Banco Nacional da Habitação (BNH) teve objetivo de instituir um órgão responsável por operacionalizar o sistema de concessão de crédito habitacional, orientando e disciplinando a habitação no país, desempenhando também a função de emprestador de última instância do SFH, garantindo a liquidez e a confiança do sistema.

Para sua sustentação financeira, o sistema possui duas principais fontes de recursos próprios utilizadas na concessão do crédito para a produção habitacional: o Fundo de Garantia por Tempo de Serviço (FGTS) - criado por meio da Lei 5.107/66, instrumento de poupança compulsória mensal, realizada pelo empregador em favor de seu funcionário, no valor de $8 \%$ do valor dos salários - um fundo de indenizações trabalhistas cuja arrecadação foi destinada à concessão de crédito à habitação e ao financiamento do saneamento básico e infraestrutura urbana - e as cadernetas de poupança, cujos recursos são captados de forma voluntária, compondo assim o Sistema Brasileiro de Poupança e Empréstimo (SBPE) (FGV, 2007).

\subsubsection{O Programa Minha Casa, Minha Vida em Campo Grande/MS - Impactos Socioeconômicos}

O Programa Minha Casa Minha Vida (PMCMV), contempla o atendimento em todas as cidades com mais de 100.000 habitantes, capitais e regiões metropolitanas, facultando aqueles municípios entre 50.000 e 100.000 habitantes para atendimento em condições especiais, e os demais municípios, pelo proposto pelo programa, não serão atendidos. A problemática sobre a qual ele foi criado: a existência de um déficit habitacional. Entretanto, o que significa o déficit habitacional? Teoricamente esse indicador representa o número de moradias que se precisa construir para que a demanda por habitações seja atendida, ou seja, pressupõe-se que haja maior demanda do que oferta de moradias. $\mathrm{O}$ conceito de déficit habitacional reflete o número de pessoas que não possui moradia ou possui moradia inadequada e esta definição não abrange o problema dos inúmeros imóveis vazios já construídos.

Pela teoria tradicional o problema habitacional reflete 
um desajuste do mercado de moradias o qual é atribuído à complexidade da produção da moradia: primeiro porque seu tempo de produção e consumo é considerado longo, o que diminui a sua velocidade de reprodução, segundo porque ela é um bem é imóvel, ou seja, deve ser produzida e consumida no mesmo espaço.

Os impactos do PMCMV no setor imobiliário podem ser também constatados em recente pesquisa publicada na Associação Brasileira de Incorporadoras Imobiliárias (ABRAINC) em parceria com a FGV (Fundação Getúlio Vargas) aponta que o déficit de moradias cresceu 7\% em apenas dez anos, de 2007 a 2017, tendo atingido 7,78 milhões de unidades habitacionais em 2017 "Chegamos ao recorde da série histórica de déficit habitacional. Hoje, ele ocorre, sobretudo, pela inadequação da moradia, famílias que dividem a mesma casa, moram em cortiços, favelas e pelo peso excessivo que o aluguel passou a ter no orçamento das famílias nos últimos anos", afirma Robson Gonçalves, da FGV.

Apesar da recente retomada do mercado imobiliário residencial, nas áreas urbanas e rurais, de Campo Grande e de Mato Grosso do Sul, as vendas e locações de imóveis comerciais continuam desaquecidas e sem perspectiva de recuperação. Segundo informações do Sindicato dos Corretores de Imóveis de Mato Grosso do Sul (Sindimóveis/ MS), nos últimos cinco anos, a procura por esta modalidade de imóveis apresentou queda de 50\% na Capital. As eleições de 2018 e a atual instabilidade política do País, aponta, seriam alguns dos motivos que travam as negociações para este tipo de empreendimento.

Outro aspecto a ser considerado foi que após cinco anos de vigência do PMCMV e diante da incerteza de sua continuidade e formatação para anos futuros representantes da construção civil insatisfeitos com desempenho econômico no país pediram mudanças na economia com reivindicações específicas para o mercado imobiliário. A principal solicitação foi a transformação do PMCMV em política permanente de Estado (LINO, 2018).

\subsubsection{Sistema Nacional de Pesquisa de Custos e Índices da Construção Civil (SINAPI)}

O Sinapi é um sistema de pesquisa mensal que informa custos e índices da construção civil, obtidos em trabalhos técnicos conjuntos da Caixa Econômica Federal e do Instituto Brasileiro de Geografia e Estatística, amparados por convênio de cooperação técnica. A rede de coleta do IBGE pesquisa mensalmente preços de materiais e equipamentos de construção, assim como os salários das categorias profissionais junto a estabelecimentos comerciais, industriais e sindicatos da construção civil, em todas as capitais dos estados.

A Caixa e o IBGE são responsáveis pela divulgação oficial dos resultados do Sinapi e pela manutenção, pela atualização e pelo aperfeiçoamento do cadastro de referências técnicas dos métodos de cálculo e do controle de qualidade dos dados disponibilizados. O Sinapi apresenta um largo campo de aplicações tais como execução e análise de orçamentos, estimativas de custos, programação de investimentos, e reajustamentos de contratos e é utilizado largamente pela CAIXA e pelo Governo Federal.

\subsection{Matriz de Insumo e Produto Exemplificando o Sinapi}

Supondo-se que cada unidade a ser construída tenha em torno de $46,15 \mathrm{~m}^{2}$ e tomando-se por base o custo do Sinapi (base 03/2018), de R\$729,99, chega-se a um custo aproximado total para cada unidade de R\$33.689,10. Multiplicando-se esse custo pelo número de unidades a serem construídas no Estado, alcança-se um montante de $27.000 \times \mathrm{R} \$ 33.689,10=$ R\$ 909.605.700,00. Se entender que esse quantitativo será aplicado até dez/19, pode-se considerar que $8 / 20$ foram ainda aplicados no exercício, de 2018, ou seja, R\$ 900.605.700,00/ $20 \times 8=\mathrm{R} \$ 363.842 .280,00$.

Tendo em vista que o custo do metro quadrado pelo Sinapi é composto pelo custo de materiais e de mão de obra, na proporção de $60,09 \%$ e $39,91 \%$, respectivamente, tem-se um montante a ser distribuído para o exercício de 2018 de R\$ 419.409.393 para materiais e um montante de R\$278.559.309 para mão de obra. Para o exercício de 2019, será investido o restante do PMCMV no valor de R\$909.605.700,00 / 20 x $12=\mathrm{R} \$ 540.363 .420,00$, na proporção de $\mathrm{R} \$ 324.704 .379,00$ para mão de obra e R\$ 215.659.041,00 para materiais de construção.

Além desse recurso carimbado, não se pode esquecer os recursos de outros programas em andamento, como o próprio orçamento do FGTS previsto para o Estado. Além dos financiamentos com origem nos recursos do Sistema Brasileiro de Poupança e Empréstimo (SBPE) - cujo histórico, conforme tabela disponível no sítio da Câmara Brasileira da Indústria da Construção (CBIC) no País representa quase três vezes o montante aplicado do FGTS. Na hipótese de serem aplicados recursos do FGTS de R $\$ 10,54$ bilhões e recursos do SBPE no montante de $\mathrm{R} \$ 30,32$ bilhões o multiplicador será de 2,88, o que se pode, seguindo essa premissa para o Estado, afirmar-se que pelo SBPE, serão aplicados mais $\mathrm{R} \$ 2.868 .605 .000,00$ por exercício o que totalizará $\mathrm{R} \$ 5.737 .211 .385,00$.

\subsection{A Política Habitacional no Brasil}

Historicamente, mesmo nos países desenvolvidos, com os mais intensos períodos de industrialização e urbanização no século XIX, o mercado imobiliário privado não foi capaz de oferecer habitações populares com condições mínimas de infra-estrutura e saneamento básico. O crédito imobiliário atingia apenas os setores dos mais favorecidos financeiramente. Apenas no final do século passado, o Estado interveio para a criação dos primeiros programas de habitação popular em alguns países da Europa Ocidental. Essas medidas foram exigidas pelos mais interessados, a população de baixa renda, mas também contou com o apoio dos grandes setores 
empresariais e legisladores conservadores.

Nos principais países da América Latina os primeiros programas ganharam força a partir da década de 1930 e 1940 em virtude da dinamização do processo de industrialização que aumentam a tendência de urbanização acelerada. A participação do Estado na definição das políticas habitacionais no Brasil iniciou decorrente deste quadro político que se configurou a partir da década de 1930, com as mudanças ocorridas no modelo econômico urbano industrial que transferiu para os núcleos urbanos as atividades econômicas e de produção.

O modelo econômico urbano-industrial pós- Revolução de 1930 levou o Estado a investir na habitação para atender as demandas populacionais, mediante a construção de casas populares, financiadas pelas carteiras prediais dos Institutos de Aposentadorias e Pensões - IAPI's. A política habitacional do Estado financiada com recursos dos Institutos de Aposentadorias e Pensões, ocasionou as primeiras iniciativas de acesso a casa própria, como também a construção de conjunto residenciais (ROMANO, 2002).

As políticas habitacionais, implantadas no Brasil, têm como objetivo garantir os direitos sociais da população, no âmbito da organização do espaço urbano para 25 fins habitacionais, ao mesmo tempo em que fortalecem o segmento da indústria da construção civil. Os limites, quanto ao atendimento das necessidades populacionais na política habitacional no Brasil, revelam o quanto o atendimento não é concebido como prioritário nos programas governamentais, o que tem resultado na ocupação desordenada do espaço urbano, especialmente pelas classes menos favorecidas.

Segundo Romano (2002), as cidades no Brasil têm crescimento desordenado, sem a devida infraestrutura de saneamento básico e demais serviços indispensáveis a oferta de qualidade de vida para a população. Assim, é possível perceber a ausência de espaços destinados à recreação e lazer, como também a funcionalidade das vias públicas, resultando em constantes congestionamentos.

\subsection{Déficit habitacional}

Há estimativas bastante diferentes do déficit habitacional no Brasil, que variam conforme a metodologia empregada. Além da Fundação João Pinheiro, o Instituto de Pesquisa Econômica Aplicada (IPEA) procuram estimar o déficit quantitativo e qualitativo de moradias no Brasil. Muito da discussão em torno da questão do déficit habitacional refere-se às significativas divergências metodológicas existentes entre as diversas alternativas de mensuração. Todavia, todas mostram que milhões de pessoas no país não dispõem de habitações adequadas, sendo em sua grande maioria famílias de baixa renda. Há famílias que moram em residências não atendidas pelo saneamento básico (abastecimento de água e esgotamento sanitário), mais de uma família coabitando uma única habitação, famílias vivendo em favelas, cortiços, dividindo um único cômodo ou salas comerciais e até embaixo de pontes, indicando que o aumento populacional nestes municípios é maior que a oferta de infraestrutura e moradia disponível à população. A definição de déficit habitacional adotada pela Fundação João Pinheiro e pelo Ministério das Cidades parte de um conceito mais amplo sobre a questão habitacional, definindo por Necessidades Habitacionais, e é dividida em dois parâmetros distintos e não excludentes: o próprio Déficit Habitacional e a Inadequação de Moradias.

O conceito de Déficit Habitacional (Figura 1), segundo o Centro de Estatística e Informação da Fundação João Pinheiro (CEI/FJP), é mais restrito e intuitivo, sendo caracterizado pela necessidade de construção de novas moradias para solução de problemas sociais e específicos de habitação em certo período do tempo. Já a Inadequação de Moradias está relacionada a problemas na qualidade de vida dos moradores, não havendo necessidade de construção de uma nova habitação, sendo que seu dimensionamento ligado a políticas de melhorias internas dos domicílios já existentes, uma vez que estes não proporcionam condições desejáveis de habitação aos moradores.

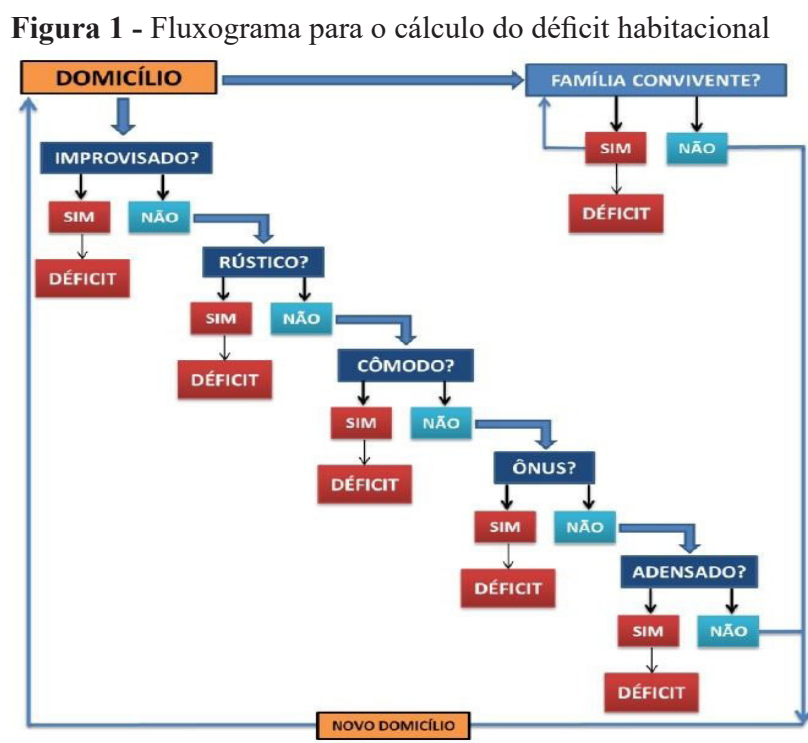

Fonte: Fundação João Pinheiro (2013).

Os fatores responsáveis pela inadequação das moradias são: adensamento excessivo de moradores em domicílios próprios, carência de serviços de infraestrutura, inadequação fundiária, cobertura inadequada e inexistência de unidade sanitária domiciliar exclusiva. (BRASIL, 2011).

\subsection{O impacto do Programa Minha Casa, Minha Vida na oferta da moradia popular na cidade de Campo Grande}

O Programa Minha Casa Minha Vida na cidade de Campo Grande apresenta um quadro limitado de atendimento da moradia destinado aos segmentos menos favorecidos. Apesar do discurso do Governo Federal em proporcionar moradia popular para superar o déficit habitacional e elevar o nível da qualidade de vida da população pobre, observa-se que os 
valores quantitativos de imóveis contratados na cidade de Campo Grande, estão aquém das expectativas projetadas pelo programa. O Quadro 1 mostra os dados apresentados pela
Planurb (Planejamento Urbano) no balanço anual de 2016 na cidade de Campo Grande, relacionados a movimentação de adesão ao programa.

Quadro 1 - Planejamento Urbano (Planurb) no balanço anual de 2016 - Campo Grande

\begin{tabular}{|c|c|c|c|c|c|}
\hline Loteamento & Região Urbana & Total de Moradias & Em Execução 2016 & $\begin{array}{c}\text { Pessoas } \\
\text { beneficiadas }\end{array}$ & Fonte de recurso \\
\hline $\begin{array}{c}\text { Residencial Rui } \\
\text { Pimentel }\end{array}$ & Anhanduizinho & 260 & 260 & 1.040 & PMCMV \\
\hline Jardim Canguru & Anhanduizinho & 272 & 272 & 1.088 & PMCMV \\
\hline Total & & 532 & 532 & 2.128 & \\
\hline
\end{tabular}

Fonte: Adaptado de PLANURB (2016).

Empreendimentos em execução, que utilizam recursos do Programa Minha Casa, Minha Vida, no município de Campo Grande. Observa-se que os dados quantitativos dos contratos firmados com alguma instituição financeira são incipientes em relação ao quadro de déficit habitacional existente na área metropolitana da cidade de Campo Grande, o que indica a limitação do atendimento da política habitacional do Governo Federal. Apesar do programa projetar em seu discurso o caráter social pautado na meta de construção de um milhão de casas populares para a população de baixa renda, percebe-se que isso não se evidencia, pois as exigências quanto ao cumprimento das regras e das normas das instituições financeiras, exclui o sonho da maioria da clientela que poderia ser contemplada com a dignidade de ter uma casa própria. Assim, é destacado o quanto o programa não consegue se materializar de fato numa ação social de caráter abrangente, e atender de fato a quem necessita. Por outro lado, é possível perceber que a presença do programa não teve impacto significativo no aquecimento do mercado da construção civil na cidade de Campo Grande, em especial, pela limitação de edificações financiadas.

Diante de tal situação, é possível considerar que tanto para a população de baixa renda quanto para o empresariado, não houve impacto considerável na efetivação do programa. O montante de vendas obtidas na comercialização das casas populares no programa minha casa minha vida na área metropolitana da cidade de Campo Grande, revela que a fragilidade da política habitacional do governo federal, seja no sentido de fortalecer o setor da construção civil, possibilitando que as empresas do setor sejam mais competitivas, como também, a limitação no atendimento das demandas da população pobre, que continuará a reivindicar alternativas de acesso a casa própria. O discurso do governo federal em promover o aceleramento do crescimento econômico e social no Brasil, ao se analisar a abrangência do programa minha casa minha vida, pode ser avaliado de forma negativa, em vista da limitação que se apresenta quanto ao fortalecimento das empresas de construção civil, que preferem, em sua maior parte, concentrar suas atividades na oferta de moradia para o segmento médio e alto, com garantia de retorno imediata do capital investido.

\section{Conclusão}

O estudo do setor imobiliário da cidade de Campo Grande, a partir da implementação do Programa Minha Casa Minha Vida e a sua relação com o setor da construção civil, aponta para um aquecimento do segmento habitacional. Após a crise econômica mundial de 2008, praticamente todos os setores do estado do Mato Grosso do Sul representaram crescimento, principalmente o da construção civil apresentou saldos altamente positivos.

Graças às iniciativas do Governo Federal, dentre elas, a implantação do programa de habitação Minha Casa Minha Vida, a crise econômica mundial não afetou o setor de construção civil, que é um dos que mais tem se destacado na economia nacional e local, com a expansão de construções de prédios residenciais tanto para as classes baixas quanto para a classe média/alta, essa mais voltada para os bairros próximos do centro da cidade.

O Programa Minha Casa Minha Vida foi lançado em março de 2009 com o objetivo de aumentar o acesso das famílias de baixa renda à casa própria e gerar emprego e renda por meio do aumento dos incentivos na construção civil.

Podemos destacar a criação do Ministério das Cidades, em 2003, que ficou responsável pela Política Nacional de Habitação, tendo como instrumentos o Sistema Nacional de Habitação e, principalmente o Programa Minha Casa Minha Vida (PMCMV), seu carro-chefe. O PMCMV se propôs a viabilizar o acesso à habitação para a população menos favorecida, através de taxas de juros abaixo das praticadas pelo mercado para o financiamento do imóvel, além de subsídios ao acesso à moradia, procurando resgatar o conceito de habitação por interesse social, momento em que o Estado brasileiro voltou a pensar em política habitacional.

A globalização da economia levou algumas empresas do setor de construção civil a ampliarem seu espaço de atuação, e, no caso da cidade de Campo Grande, a fusão das empresas de construção civil local com demais empresas. Empresas com grande experiência no mercado nacional resolveram investir no mercado sul mato grossense devido ao relevante déficit habitacional e ao grande espaço que ainda havia para o segmento.

Conclui-se que, o setor imobiliário da cidade de Campo 
Grande teve impactos significativos para as empresas de construção civil, decorrentes da operacionalização do Programa Minha Casa Minha Vida, em função do mercado imobiliário apresentar potenciais significativos de atendimento das demandas da classe alta, média e baixa.

\section{Referências}

ABECIP. O crédito Imobiliário no Brasil: caracterização e desafios. São Paulo: FGV Projetos, 2007.

BELLONI, I. Metodologia de avaliação em políticas públicas: uma experiência em educação profissional. São Paulo: Cortez, 2001.

BONDUKI, N.G. Habitação popular: contribuição para o estudo da evolução urbana de São Paulo. In: VALADARES, L. Repensando a habitação no Brasil. Rio de Janeiro: Zahar Editores, 1983.

FUNDAÇÃO JOÃO PINHEIRO. Centro de Estatística e Informações. Déficit Habitacional Municipal no Brasil 2010. Belo Horizonte: Fundação João Pinheiro 2013.

MARQUES, C.G. Evolução histórica do SFH. Rev. Esmafe, n.9, 2005. Disponível em: <https://www.researchgate.net/ publication/41441354_Evolucao_historica_do_SFH>. Acesso em? 9 jun. 2019.

GUBA, E.G.; LINCOLN, Y.S. Paradigmatic controversies, contradictions, and emerging confluences. In: THE SAGE HANDBOOK OF QUALITATIVE RESEARCH. Thousand Oaks: Sage, 2005, p.191-215.

MINAYO, M.C. Pesquisa social: teoria, método e criatividade. Petrópolis, Vozes, 2002.

LINO, C. Mercado vê desaquecimento na venda de imóveis. Correio do Estado, 2018.

LUDKE, M. Pesquisa social. São Paulo: EDUSP, 2006.

SANTOS, M. Espaço e método. São Paulo: Nobel, 1997.

ROMANO, C.S. Políticas Sociais e Habitacionais no Brasil. Rev. Serviço Social, v.2, n.10, 2002.

SANTOS, J.G.C.; CALÍOPE, T.S.; BARROS NETO, J.D.P. Sessão especial - Fast Track Segurança Saúde do Trabalhador na indústria da Construção Civil. 2017. Disponível em: $<$ https:// cbic.org.br/wpcontent/uploads/2019/07/Seguranca Saude do Trabalho_na_Industria_da_Construcao_Civil.pdf $>$ Acesso em: dez. 2019. 